\title{
Applied Research in Quality of Life (ARQOL): Where Are We and Issues for Consideration
}

\author{
Daniel T. L. Shek
}

Published online: 27 June 2014

(C) Springer Science+Business Media Dordrecht and The International Society for Quality-of-Life Studies (ISQOLS) 2014

It is indeed my honor to take up the editorship of Applied Quality of Life (ARQOL), the official journal of the International Society for Quality-of-Life Studies. According to the founding editors of the journal, ARQOL "focuses on publishing conceptual and methodological papers dealing with quality-of-life studies in the applied disciplines of the social and behavioral sciences" (Michalos et al. 2006, p.1). With the observation and firm belief that here is a gap in the field of applied quality of life, ARQOL attempts "to fill a major gap in the growing field of quality-of-life studies. This gap is the lack of a journal that focuses on applied social and behavioral sciences. The goal is to fill a growing niche in applying quality-of-life concepts, models, methods, and indicators to inform decision makers" (Michalos et al. 2006, p.3). As stated in the journal home page, ARQOL publishes "conceptual, methodological and empirical papers dealing with quality-of-life studies in the applied areas of the natural and social sciences. It aims to publish papers that have direct implications for, or impact on practical applications of research on the quality of life". In short, ARQOL is a journal devoted to the publication of a wide range of papers on QOL which have direct implications to QOL or application of QOL concepts.

What has ARQOL accomplished since its inception? When I read the 2012 Publisher's Report prepared by Springer, my impression is that as a new journal, the journal has grown tremendously in terms of the number of papers submitted and accepted which have been written by scholars and researchers throughout the world. ARQOL also has its impact factor which is a clear indication that it has influence in the academic and professional communities on applied QOL issues.

With these achievements, I must give a salute to the three founding editors for their great effort which has shaped the healthy and positive development of the journal. Without them, we simply cannot have a journal that we are proud of. I must also thank the International Society for Quality-of-Life Studies for appointing me to this position. I must confess that when I knew I had been elected to be the Editor-in-Chief of ARQOL, my feelings were mixed. On the one hand, I felt extremely honored to be entrusted with

D. T. L. Shek $(\bowtie)$

Department of Applied Social Sciences, The Hong Kong Polytechnic University, Hong Kong,

Hong Kong

e-mail: Daniel.shek@polyu.edu.hk 
this important task and I felt excited about the future development of the journal. On the other hand, I felt the subtle burden because of the outstanding work of the three founding editors.

As the new Editor-in-Chief of ARQOL, I will continue to recruit international renowned QOL scholars to serve on the Editorial Board. Besides, consistent with the practice of many leading journals, I will seriously consider fixing the term of office of editorial members so that we will have tighter corporate governance.

I would like to share with you my vision about the journal and the issues deserving our consideration.

- International perspective: As applied research on quality of life is a prime concern for people throughout the world and there are cultural variation in its manifestation, meaning and application, contributions from researchers from different parts of the world can definitely help to chart a global contour of applied QOL. My rough impression is that papers in the field of QOL have been commonly written by scholars in North America, Europe and Australia. With the rapid social and economic changes in different parts of the world, including Asia, Russia, Eastern Europe, Middle East, Africa and South America, it would be exciting to consider submissions by scholars in these areas.

- Inter-disciplinary and multi-disciplinary focus: The website of the journal states that "ARQOL guides decision making in a variety of professions, industries, nonprofit, and government sectors, including healthcare, travel and tourism, marketing, corporate management, community planning, social work, public administration, and human resource management. It helps decision makers apply performance measures and outcome assessment techniques based on such concepts as well-being, human satisfaction, human development, happiness, wellness and quality-of-life". We will continue to adopt an inter-disciplinary and multidisciplinary approach to address the issue of applied QOL. Researches on Government policies and provisions are important because they affect every member of a society, although evidence-based public policies and services are still at their infancy in many parts of the world. Besides, some good practice in the business sector such as work-life balance and family friendly policies can definitely be seriously considered by the Government and non-governmental organization sectors.

- Innovative initiatives on applied QOL: Many global issues are becoming more complex and persisting, such as poverty, rich-poor divide, inter-group conflict, over-population, pollution, global warming, globalization, and family disorganization. These changing global issues call for innovative perspectives, research, services and policies. In particular, we can learn from each other in different societies and cultures. Obviously, ARQOL provides a good platform to disseminate innovative practice on applied QOL.

- Inclusion of research based on different methodologies: In social and behavioral sciences, there has been a continued debate on the role of quantitative and qualitative methodologies. In the field of QOL, quantitative methodologies such as social indicators surveys and statistical analyses are the mainstream approach. Nevertheless, there has been a growing emphasis on qualitative and mixed research methods in understanding and applying QOL. For example, in the field of 
evaluation, while randomized controlled trials are still regarded as the "gold standard", many evaluation studies also focus on the subjective experience and social construction of the program effects based on the views of different stakeholders. To obtain a triangulated view of applied QOL, inclusion of different research studies in the picture is desirable.

- Integration of theory and practice on $Q O L$ : When we talk about applied research, there are two common myths. First, some researchers might say that basic research on QOL should not be considered in the applied QOL context. Second, some people simply believe that it is easy to apply scientific knowledge on QOL. Regarding the first myth, we must ask what the basis of application is. Obviously, basic research is the "soul" of application. For example, without the basic research on optical fibers, the quality of Internet connection cannot be enhanced. Another example is family life education. Without research on attitude change and ecological influences, it would be quite impossible to design effective family life education which can eventually promote family QOL. Hence, researches utilizing QOL theories and frameworks are not unimportant. Regarding the second myth, we simply cannot assume that QOL research findings can be easily put to application because we need time to accumulate relevant research evidence. For ARQOL, we focus on conceptual, methodological and empirical papers and we welcome papers on an integration of theories and applied research on QOL. Using the Chinese concept of "Yin" and "Yang", we regard both theories and applications on QOL to be two sides of the same coin. In the "Book of Changes" (I Ching), there is the saying of "kāi wù chéng wù" (learn every truth and utilize the knowledge learned to accomplish every task). The literal meaning is that when we understand the basic nature of things, we will be able to do things in a better manner. Obviously, learning about the nature of QOL would help to apply it in different contexts.

- Illumination of the importance of applied QOL: While it is important to understand the basic nature of QOL, it is equally important not to underestimate the importance of application of knowledge to promote QOL. If we look at research in the social and behavioral sciences, most of the work is devoted to basic understanding. As mentioned above, while research promoting basic understanding is important, how to apply such knowledge to the betterment of QOL in human beings is even more important. In my work on positive youth development, besides looking at the relationships amongst positive youth development, life satisfaction and adolescent risk behavior (i.e., basic research), we have designed a program which has been found to effectively promote the holistic development of Chinese adolescents (i.e., applied research; Catalano et al. 2012; Shek and Sun 2013a, b). A famous Chinese scholar and the high Chancellor of the Song Dynasty remarked in "Da Kong Wen Zhong Si Hu Shu" that the most critical step in academic study is how to apply the acquired knowledge after learning, instead of merely understand the subject matter (“xué zhě guì yú xíng zhī, ér bù guì yú zhī zh $\vec{i}$ ).

- Impact of research: As a journal devoted to applied research on quality of life, we are very concerned about the impact of QOL research work. Hence, besides on statistical significance of research findings, practical significance and impact of research findings should also be seriously considered. Of course, another focus of colleagues may be on the "impact factor" of ARQOL. While we welcome the fact 
that ARQOL has an impact factor and SSCI impact factor is something we should not ignore, I personally do not think it is appropriate to have a morbid emphasis on impact factor because it will divert attention of colleagues to conduct meaningful QOL research.

If we take the first letter in the first word of the above points, we have seven "i". In an " $i$ " age, these points provide useful pointers for the future development of ARQOL.

\section{References}

Catalano, R. F., Fagan, A. A., Gavin, L. E., Greenberg, M. T., Irwin, C. E., Ross, D. A., \& Shek, D. T. L. (2012). Worldwide application of prevention science in adolescent health. Lancet, 379, 1653-1664.

Michalos, A. C., Sirgy, M. J., \& Estes, R. J. (2006). Introducing the Official Journal of the International Society for Quality-of-Life Studies: Applied Research in Quality of Life (ARQOL). Applied Research in Quality of Life, 1, 1-3.

Shek, D. T. L., \& Sun, R. C. F. (2013a). Development and evaluation of Positive Adolescent Training through Holistic Social Programs (P.A.T.H.S.). Germany: Springer.

Shek, D. T. L., \& Sun, R. C. F. (2013b). The Project P.A.T.H.S. in Hong Kong: Development, training, implementation, and evaluation. Journal of Pediatric and Adolescent Gynecology, 26, S2-S9 